\title{
Examining the Potential of Using Information on Fire Detected by MODIS and Socio-Economic Variables to Highlight Potential Coca Cultivations in Forest Areas in Colombia
}

\author{
Adriana Gomez ${ }^{*}, 1$, Coen Bussink ${ }^{2}$, Thomas Bauer ${ }^{1}$, Steffen Fritz ${ }^{3}$, Antonio Escobar ${ }^{4}$, Mykola Gusti $^{3}$, \\ Linda $\mathrm{See}^{3}$ and Clement Atzberger ${ }^{1}$
}

\author{
${ }^{I}$ International Institute for Applied Systems Analysis (IIASA), Laxenburg, Austria ; affiliation 2: Lviv Polytechnic \\ National University, Lviv, Ukraine \\ ${ }^{2}$ United Nations Office on Drugs and Crime, Vienna International Centre, Wagramerstasse 5, Vienna, Austria \\ ${ }^{3}$ International Institute for Applied Systems Analysis (IIASA), Laxenburg, Austria \\ ${ }^{4}$ Vienna University of Economics and Bussines Administration, Liniengasse 9, Vienna, Austria
}

\begin{abstract}
Fires in forest areas are considered an important threat to the Andean Region and the Amazon rainforest. In Colombia, fire is used to expand the agricultural frontier (including illicit crops) which results in deforestation. Given the importance of avoiding deforestation and to control coca expansion, this paper aims to: 1) understand the relationship between fires and deforestation, coca and deforestation and hence coca and fires; 2) examine the potential of using fire data from remote sensing and socio-economic variables to predict the occurrence of new coca fields in forest areas in Colombia. The analysis was undertaken over a ten year period (2000-2010) at a municipality level in two areas with high coca dynamics (Central Region and Putumayo - Caquetá) using Pearson correlation and three different models: a Linear Probability model, a Logit model and a Probit model. The results show that there is a positive relationship between fire and deforestation. Although in general the correlation between coca and deforestation is positive, it differs at the municipality level depending upon the area of forest cover and the coca plot size. The results of the Logit and Probit models show that fire and expulsion, which is a measure of forced displacement by violence, can be used as indicators to highlight coca expansion in forest areas.
\end{abstract}

Keywords: Coca, deforestation, fires, logit model, probit model, remote sensing.

\section{INTRODUCTION}

There are innumerable factors contributing to deforestation of tropical forests in Colombia such as agriculture, cattle ranching, population pressure and illicit crops. In most cases, fire is used to open up new areas for human activities [1]. In Colombia the rate of deforestation was $101,000 \mathrm{Ha} /$ year between 1990 and 2010, according to the Food and Agriculture Organization of the United Nations (FAO) [2]. However, the Colombian government reported that the rate of deforestation for the same period was $310,349 \mathrm{Ha} / y e a r$ [3]. Slash and burn land use practices are one of the most commonly used techniques in the tropics to clear forest areas, resulting in deforestation and forest degradation [4]. The increased demand for land results in a higher risk of forest loss and in a modified fire regime, with the ocurrence of a higher number of fires in the wet period compared to the drought period [5]. There have been a number of studies in the past outlining the relationship

*Address correspondence to this author at the Institute of Surveying, Remote Sensing and Land Information, University of Natural Resources and Life Sciences, Peter-Jordan-Straße 82, Vienna, Austria;

Tel: +436801400078; Fax: +43-1-47654-5142;

E-mails: ivfl@boku.ac.at, adgomezs@outlook.com between fires and deforestation using remotely sensed data such as MODIS, ATSR, VIRS and AVHRR [6, 7]. The detection of vegetation fires by remote sensing has been used to identify areas of rapid land cover change [6] as well as understanding the influence of climate in fire occurrence $[8$, 9]. In another study the relationship between fire activity and land-cover change was found to vary with climate, the amount of biomass and different land use practices [10].

The relationship between fire and coca has been analyzed in Northwestern Amazonia where the use of fire to establish illicit crops was not detected [11]. However, it is clear that coca plantations in forests will increase the probability of forest loss, especially in southern Colombia, since the sequence of a coca crop cycle starts with the clearing of primary and secondary forests, removing the bulk material followed by burning [12]. It has also been shown that coca is a driver of deforestation [13, 14]. In Peru, coca plantations have been responsible for $10 \%$ of the total deforestation during the twentieth century [13] and this impact is even more noticeable in Colombia and Bolivia [15].

It is common to find coca crops in places with high poverty and illiteracy rates which can be associated with social, economic, environmental and institutional factors at the local scale [16]. Coca regions tend to have similar socio- 
economic conditions such as high levels of unsatisfied basic needs of the population, rural populations, a limited level of municipal development and high levels of forced displacement and homicides. Moreover, areas with high coca crop occurrence tend to have a low road density, the presence of illegal groups and a high percentage of forest cover [17].

Coca in Colombia has a long history and the degree of impact on forests has been different across the regions. The measures taken to control coca cultivation in Colombia, such as manual eradication and aerial spraying, are also partly responsible for coca expansion since this has forced growers to move into the forest in order to hide their coca crops and cultivate in small and dispersed plots [18]. Furthermore, this has led to the expansion of the agricultural frontier as people in these areas also grow additional non-coca crops [19].

Our hypothesis is that the increase of fire in places around existing coca cultivation can highlight the expansion of coca crops. In this study, we first analyze the relationship between fires, coca and deforestation and then consider the impact of available socio-economic variables such as the number of inhabitants in rural areas, unsatisfied basic needs and the expulsion of people by violence. Finally, we examine the potential of using remotely sensed fires to predict potential coca field locations in forest areas across eight departments (526 municipalities) in Colombia for the years 2000 to 2010 .

\section{STUDY AREA AND DATA}

\subsection{Study Area}

Fig. (1) shows the location of the study area in Colombia, which considers two main regions: Central Region and Putumayo-Caquetá. Three aspects were taken into account to select the regions: high coca dynamics, forest cover and availability of data. The departments of the Central Region considered here include Cordoba, Bolivar, Santander, Cundinamarca, Boyacá and Antioquia which are located in part over the Andean Mountains. The departments of Putumayo and Caquetá are located in the Amazon region. All of these regions have had high coca dynamics during the last decade and coca cultivation has also occurred in these forest areas [20].

The Central Region covers different ecosystems. The crops found in 2010 are just $2 \mathrm{~km}$ away from the ones found in 2001, meaning that new crops are found close to the established areas. The expansion is taking place in the direction of the mountains as well as within this zone. In 2000 the areas with large coca cultivations were Norte de Santander and the south part of Bolivar. Five years later the expansion of coca took place in Antioquia, and more recently, Norte de Santander has seen a reduction in coca areas [20].

Putumayo-Caquetá is one of the most stable coca regions in Colombia. New plots of coca have also been found at a distance of $2 \mathrm{~km}$ from the old plots, meaning that the expansion of coca is happening around a central nucleus. Moreover, the density of the cultivation has decreased significantly during the last 10 years, especially in Valle del Gamúez, San Miguel and Cartagena del Chaira [20].
Colombia is divided politically into departments, which are further subdivided into municipalities. Each municipality has political, fiscal and administrative autonomy within the limits indicated under Colombia's constitution. The departments perform complementary actions, and they are the bridge between the national government and the municipalities (Colombia's Constitution Article 298 and 311).

\subsection{Input Data}

\subsubsection{Coca Dataset}

The coca datasets were provided by the United Nations Office on Drugs and Crime (UNODC) Colombia under the Integrated System of Illicit Crop Monitoring (SIMCI) project. The coca data are expressed as area in hectares for each $1 \mathrm{~km}$ grid cell as a raster layer provided for the two regions of the study area. Raster data layers were available as a yearly time series from 2000 to 2010 . In addition, the data layers contain information regarding the municipality to which each $1 \mathrm{~km}$ grid cell belongs.

These grids were used to calculate the coca increment at each grid cell, which we define here as the sum of any increases in the area of coca cultivation between the subsequent and previous year, calculated for each consecutive pair of years for the period 2000 to 2010 . Finally, the hectares of coca increment at municipality level was calculated by summing up all the coca increments at each grid cell beloging to the each municipality as follows:

coca increment $=\sum_{t=2001}^{2010} \max \left(0, \operatorname{coc} a_{t}-\operatorname{coc}_{t-1}\right)$

The procedure is illustrated in Fig. (2). Note that only the positive values or increases in coca are considered when the current year's coca grid is subtracted from the previous one. Consequently, decreases in coca or stable coca areas are not considered relevant to this analysis. To clarify, the final value does not show the yearly trend of increase or decrease of coca as it is an accumulated value for the 10 years of analysis.

\subsubsection{Forest Cover}

Forest cover data for the year 2000 were obtained from the REDD (Reducing Emissions from Deforestation and Degradation) project entitled 'Scientific and institutional capacity building to support REDD in Colombia' at a $30 \mathrm{~m}$ resolution [3]. A $1 \mathrm{~km}$ forest mask for the year 2000 was created by aggregating the original forest non-forest map to match the coca data. All pixels with $80 \%$ or more of forest cover were classified as forest. This data set was used to build the model and to analyze the relationship between coca increment and fire in forest areas.

The deforestation map for the period 2000-2005 was obtained from the project mentioned above. The deforestation map from 2005-2010 was calculated from the forest-non forest maps for 2005 and 2010.

\subsubsection{Active Fires}

The fire data were downloaded from the Fire Information for Resource Management System (FIRMS) (http://firefly. geog.umd.edu/firms/ (Accessed 2013)). The data contain 


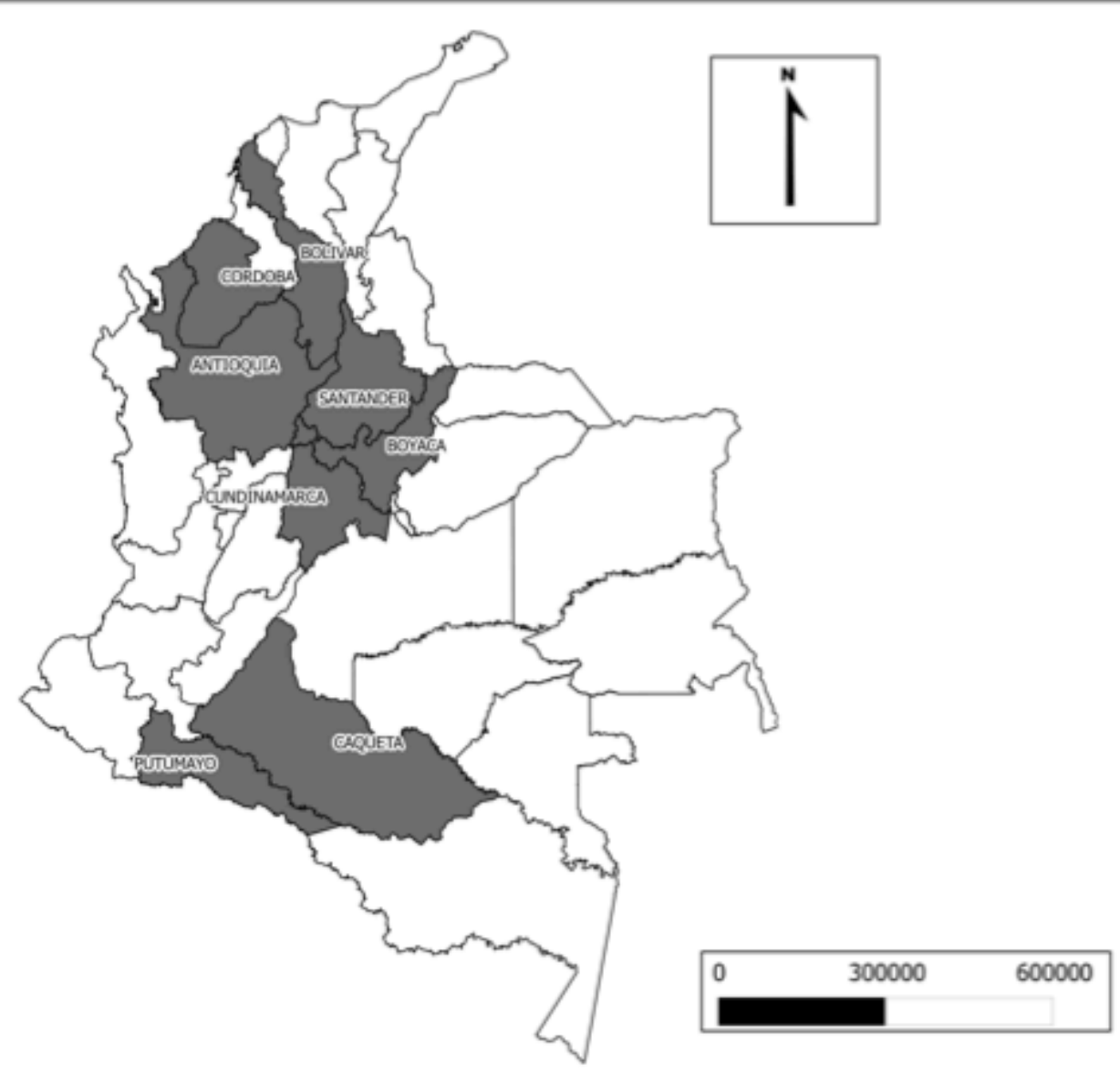

Fig. (1). Regions under study.

hotspot fires detected by the MODIS Rapid Response System, which delivers near real-time information [21]. The MODIS active fire product detects fires in a $1 \mathrm{~km}$ pixel that are burning at the time of overpass under relatively cloudfree conditions using a contextual algorithm [22]. The dataset was available for each year between 2000 and 2010 . The number of forest fires per municipality was extracted by using the forest mask described above.

The relationship between fire and deforestation was analyzed using Pearson correlation, which is a measure of the strength of the linear dependence between two variables. Pearson correlation has been used to identify the relationship between socio-economic variables such as population density, population growth rate, extent of forest area, total land area and foreign exchange earned through the export of forest products and deforestation over 141 countries in different continents [23].

The number of fires per municipality was computed in order to determine whether fires are associated with different coca related classes. Three classes were defined within each municipality. The first class was the density of fires per area of coca increment, the second class was the density of fires per non-coca area (areas with no coca plantations for the period $2000-2010$ ) and the third class represents the density of fires in stable or decreasing coca areas (areas with coca plantations but without any increment for the period
$2000-2010$ ) (see Fig. 3). The density of fires was then calculated as the number of fires in the forest divided by the corresponding area.

\subsubsection{Socioeconomic Variables}

Three socioeconomic variables were taken into account for the analysis: number of inhabitants in rural areas, unsatisfied basic needs and expulsion. Inhabitants in rural areas refer to the number of people living outside of urban areas (DANE 2012). Unsatisfied basic needs is an indicator of poverty $(\%)$. It determines if the basic needs of the population are met based on indicators such as inadequate housing, crowded housing, housing with inadequate services, housing with high economic dependence and housing with school age children who are not attending school [24]. Expulsion is a measure of forced displacement by violence (number of persons/year). Expulsion often takes place when illegal groups such as the FARC are present [25]. It has been shown that in many cases the geographical intensification of the conflict is the principal cause of expanding illicit crop production [26]. The first two datasets were obtained from the National Department of Statistics (DANE) in Colombia from the census of 2005. The last dataset was obtained from Social Action in Colombia (currently the Department for Social Prosperity - DPS) annually for the period 2000 to 2010. 
A.

\begin{tabular}{|l|l|l|l|l|}
\hline 5 & 7 & 1 & 5 & 0 \\
\hline 2 & 4 & 9 & 3 & 3 \\
\hline 4 & 7 & 4 & 8 & 8 \\
\hline 1 & 5 & 9 & 7 & 6 \\
\hline 6 & 0 & 3 & 9 & 6 \\
\hline
\end{tabular}

Coca 2001

B.

\begin{tabular}{|l|l|l|l|l|}
\hline 4 & 6 & 2 & 3 & 4 \\
\hline 1 & 4 & 3 & 5 & 7 \\
\hline 9 & 0 & 1 & 0 & 2 \\
\hline 0 & 3 & 8 & 1 & 9 \\
\hline 0 & 3 & 1 & 3 & 9 \\
\hline
\end{tabular}

Coca 2000

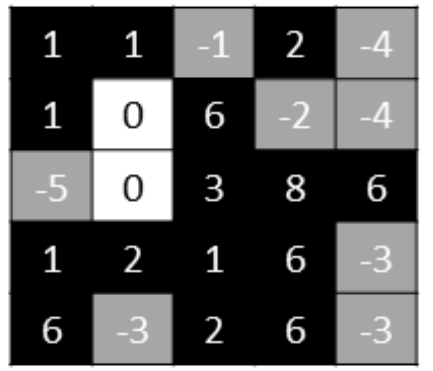

\begin{tabular}{|l|l|l|l|l|}
\hline 0 & 2 & 7 & 2 & 7 \\
\hline 6 & 2 & 9 & 8 & 9 \\
\hline 4 & 5 & 2 & 9 & 3 \\
\hline 1 & 3 & 1 & 6 & 6 \\
\hline 1 & 4 & 0 & 5 & 4 \\
\hline
\end{tabular}

Coca 2002

\begin{tabular}{|c|c|c|c|c|}
\hline-5 & -5 & 6 & -3 & 7 \\
\hline 4 & -2 & 0 & 5 & 6 \\
\hline 0 & -2 & -2 & 1 & -5 \\
\hline 0 & -2 & -8 & -1 & 0 \\
\hline-5 & 4 & -3 & -4 & -2 \\
\hline
\end{tabular}

\begin{tabular}{|l|l|l|l|l|}
\hline 5 & 7 & 1 & 5 & 0 \\
\hline 2 & 4 & 9 & 3 & 3 \\
\hline 4 & 7 & 4 & 8 & 8 \\
\hline 1 & 5 & 9 & 7 & 6 \\
\hline 6 & 0 & 3 & 9 & 6 \\
\hline
\end{tabular}

Coca 2001 c.

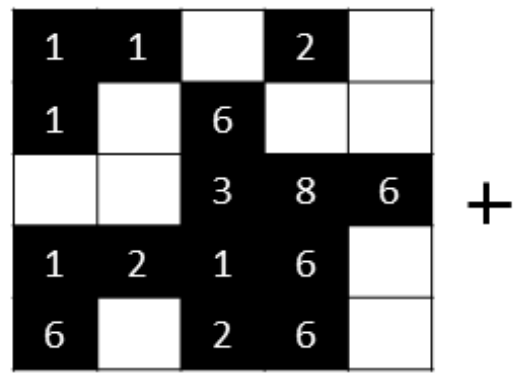

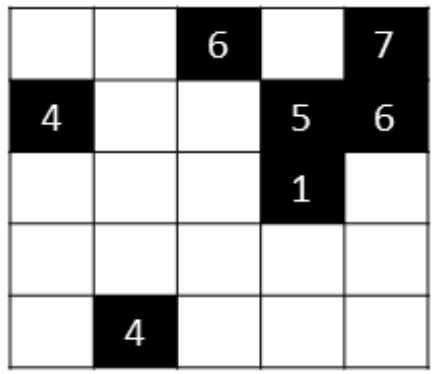
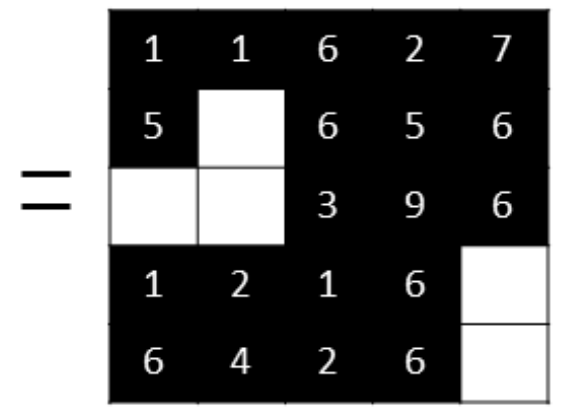

Fig. (2). Representation of the coca increment calculation.

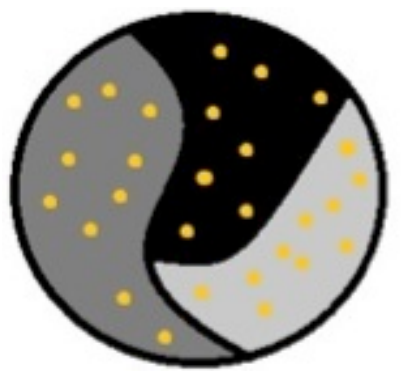

Coca increment area

Non coca area

Stable/decreasing coca area

Fire

Fig. (3). Classification of areas.

\section{METHODS}

The statistical analysis was divided into two parts. The first part aimed to identify if there was a relationship between fire and deforestation and coca and deforestation based on the density of fires per municipality. A Pearson correlation analysis was undertaken to determine the relationship between the coca increment and fires occurring in forest areas and the coca increment in deforested areas per municipality in order to observe the impact of coca in forest areas.

The second part aimed to build a model to identify if fire in forest areas and socio-economic variables can be used to highlight potential coca increments in forest areas. These models are described below.

\subsection{Model Development}

A Linear Probability Model (LPM), a Logit model and a Probit model were applied in this research. These models assume that the dependent variable is binary, i.e., it takes values of 0 (FALSE) or 1 (TRUE). In our case, the dependent variable is the increase in cocaine plantations $\left(\mathrm{coc}_{-} \mathrm{pl}_{\mathrm{i}}\right)$ and can be expressed using an indicator function as follows:

$c O c_{-} p l_{i}=\mathbf{1}_{\left[c o c_{-} p l_{i, 2010}-c o c_{-} p l_{i, 2000}>0\right]}$

In this line of reasoning, we refer to success and failure when the dependent variable is equal to 1 and 0 , respectively. Only those municipalities with complete data for all of the variables were selected. The data were aggregated to 526 municipalities in Colombia. In the LPM, 
$\beta_{j}$ measures the change in the probability of success (TRUE) when $x_{j}$ increases by one unit of the underlying measures, which is either number of fires, number of inhabitants, percentage of unsatisfied basic needs of the population or number of people expulsed, holding the other variables fixed:

$$
\begin{aligned}
& \Delta P\left(\text { coc }_{-} p l_{i}=1 \mid x\right)=\beta_{j} \Delta x_{j} \\
& \text { coc }-p l_{i}= \\
& \beta_{0}+\beta_{1} \text { fires }_{i}+\beta_{2} \log \left(\text { inhab }_{i}\right)+\beta_{3} \text { needs }_{i}+ \\
& \beta_{4} \log \left(\operatorname{expl}_{i}\right)+U_{i}
\end{aligned}
$$

where $i$ is the municipality, $c o c \_p l_{i}$ is the increment in coca plantations; fires $_{i}$ is the total number of fires in forest areas between 2000 and 2010; inhab $b_{i}$ is the total number of inhabitants in rural areas based on the data from the 2005 Census; need $s_{i}$ are the basic unsatisfied needs based on the data from the 2005 Census (expressed as a \% of basic needs); and $\operatorname{expl}_{i}$ is the total expulsion between 2000 and 2010 .

Eq. (2) can be re-expressed as follows for the Logit and Probit models:

$$
\begin{aligned}
& P\left(\text { coc_pl }_{i}=1 \mid x\right)=\mathrm{G}\left(\beta_{0}+\beta_{1} \text { fires }_{i}+\beta_{2} \log \left(\text { inhab }_{i}\right)+\right. \\
& \left.\beta_{3} \text { needs } s_{i}+\beta_{4} \log \left(\operatorname{expl}_{i}\right)\right) \quad P\left(\left(\text { coc_pl }_{i}=1 \mid x\right)=\mathrm{G}\left(\beta_{0}+\right.\right. \\
& \left.x \beta_{1}\right)
\end{aligned}
$$

where $G$ is a function that produces values between 0 and 1 for all real number inputs. This ensures that the estimated response probabilities are strictly between zero and one. For a Logit model, $G$ is a logistic function or cumulative distribution function for a standard logistic random variable as follows:

$$
G(z)=\frac{\exp (z)}{1+\exp (z)}=\Lambda(z)
$$

while $G$ is the standard cumulative distribution function expressed as an integral for a Probit model:

$$
G(z)=\Phi(z) \int_{-\infty}^{z} \varphi(v) d v
$$

\subsection{Cross-Validation}

Cross-validation is a method for estimating generalization error based on resampling. The 10 fold crossvalidation method has the advantage that all observations are used for both training and validation, and each observation is used for validation exactly once. This leads to a more accurate way to measure how efficiently the algorithm has 'learned' a concept based on the input data [27]. Leave-oneout cross-validation (LOOCV) is a method where $\mathrm{K}$ equals the number of observations and the model is tested on one observation multiple times [27].

\section{RESULTS}

\subsection{Density of Fires}

Fig. (4) shows a classification of the municipalities based on fire density. It can be observed that in the central region, most of the municipalities have a higher density of fires in coca increment areas than in areas with non-coca increment. In Putumayo the situation is similar to the central region but
Caquetá exhibits a different behaviour where the largest municipalities have a higher density of fires in the stable or decreasing coca areas.

When comparing municipalities with forest fires in coca increment areas and municipalities without forest fires in coca increment areas at the department level, it can be seen that the major coca increment during the period 2000 to 2010 per department is found in the municipalities with forest fires in coca increment areas (see Tables 1 and 2). When undertaking the same comparison but using coca increment only in forest areas, a similar situation is presented. For example, in Antioquia, there are 125 municipalities in total where 32 municipalities had fires related to coca increment, representing $98.5 \%$ of the total coca increment for the whole period $(2000-2010)$. A further 15 municipalities did not have fires but the coca increment was very low, i.e. $1.49 \%$ of the total $(100 \%)$ for the period 2000-2010. The remaining municipalities in Antioquia had no coca at all during the period.

\subsection{The Relationship Between Fires, Coca Increment and Deforestation}

The results of the Pearson correlation coefficient between fires and deforestation show a strong relationship between the number of fires and the area of deforestation $(\mathrm{r}=0.930 ; \mathrm{p}$ $=0.01$ ). This is not a surprising result since fire is the most commonly used tool to expand the agricultural frontier.

The correlation coefficient between the coca increment and deforestation in the last ten years is 0.729 and highly significant at a 0.01 level. Although correlation cannot be used to indicate causality, there are many studies showing that the expansion of cropland, including coca plantations, is driving deforestation [28]. This indicates the existence of an indirect but strong link in the dynamics between fire, pastures and illicit crops [11].

\subsection{Model Results}

Using the data and methods outlined previously, the LPM, Probit and Logit models can be expressed as follows:

LPM:

$P\left(\operatorname{coc}_{p l_{i}}=1 \mid x\right)=-.6477+0.0004 *$ fires $_{i}+0.0245 *$
$\log \left(\right.$ inhab $\left._{i}\right)+0.0042 *$ needs $_{i}+0.065 * \log _{\left(\operatorname{expl}_{i}\right)}$

Logit:

$P\left(\right.$ coc $\left._{p_{i}}=1 \mid \boldsymbol{x}\right)=G\left[-9.1721+0.4973 *\right.$ fires $_{i}+$

$0.1152 * \log \left(\right.$ inhab $\left._{i}\right)+0.0288 *$ needs $_{i}+0.5544 *$ $\left.\log \left(\operatorname{expl} l_{i}\right)\right]$

Probit:

$P\left(\operatorname{coc}_{p l_{i}}=1 \mid x\right)=G\left[-4.468+0.2788 *\right.$ fires $_{i}+$

$0.0156 * \log \left(\right.$ inhab $\left._{i}\right)+0.0146 *$ needs $_{i}+0.2926 *$

$\left.\log \left(\operatorname{expl} l_{i}\right)\right]$

All these results are summarized in Table $\mathbf{3}$ below. However, note that the coefficients for the Logit and Probit models do not have a direct interpretation due to the presence of the function G(.) (logistic and cdf function, respectively). In order to calculate the marginal effects, a scale factor is needed. In our research, we used the average 


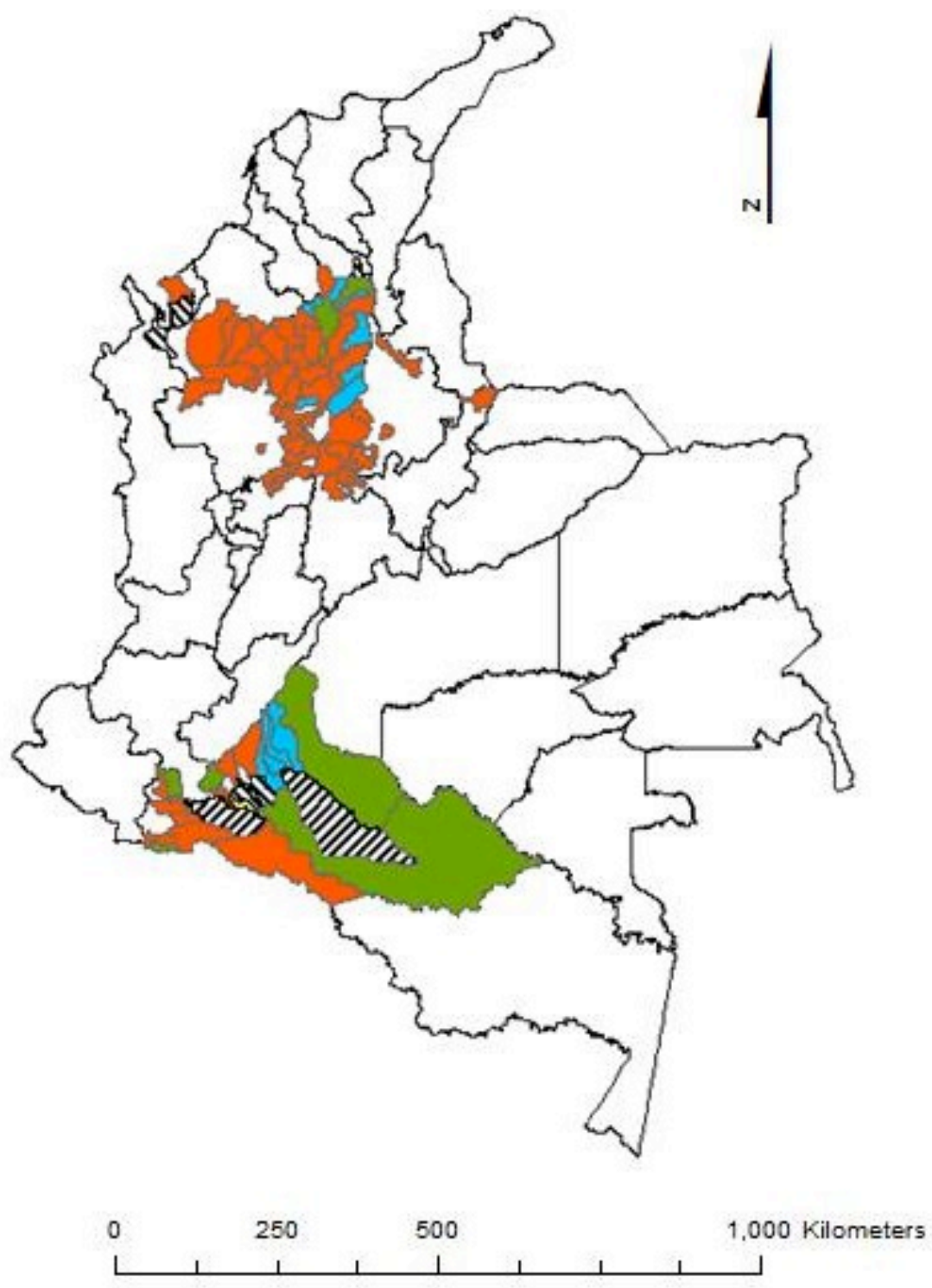

\section{Classification of density of fires}

Density higher in coca increment areas

Density higher in non coca areas

Density higher in stable/decreasing coca areas

WDensity in coca increment areas = Density in stable/decreasing coca areas

MDensitv in coca increment areas = Densitv in non coca areas

Density in non coca areas $=$ Density in stable/decreasing coca areas

Fig. (4). Density of fires.

partial effect (APE) approach, which basically averages the individual partial effects across the sample. For a continuous explanatory variable, $x_{j}$, the APE is:

$$
\left[\frac{1}{n} \sum g\left(\hat{\beta}_{0}+\boldsymbol{x}_{\boldsymbol{i}} \widehat{\boldsymbol{\beta}}\right)\right] \hat{\beta}_{j}
$$
where $\left[\frac{1}{n} \sum g\left(\hat{\beta}_{0}+\boldsymbol{x}_{\boldsymbol{i}} \widehat{\boldsymbol{\beta}}\right)\right]$ is the scale factor and the function
$\mathrm{g}($.$) is$ $\mathrm{g}(\mathrm{z})=\frac{\exp (\mathrm{z})}{[1+\exp (\mathrm{z})]^{2}}$

and

$g(z)=\phi(z)=(2 \pi)^{-1 / 2} \exp \left(-\frac{z^{2}}{2}\right)$

for the Logit and Probit model, respectively. The scale factors for our particular model are 0.2436 for the former and 0.3799 for the latter model. Then, the models above can be rewritten as follows: 
Table 1. Comparison between municipalities with and without forest fires in coca increment areas (2000 - 2010). Note that a very high percentage of coca increment occurred in municipalities where forest fires were detected.

\begin{tabular}{|c|c|c|c|c|c|}
\hline \multirow{2}{*}{ Department } & \multirow{2}{*}{$\begin{array}{c}\text { Total Coca } \\
\text { Increment (ha) }\end{array}$} & \multicolumn{2}{|c|}{$\begin{array}{l}\text { Municipalities with Fires in } \\
\text { Coca Increment Areas }\end{array}$} & \multicolumn{2}{|c|}{$\begin{array}{l}\text { Municipalities without Fires in } \\
\text { Coca Increment Areas }\end{array}$} \\
\hline & & Number of Municipalities & $\%$ of Coca Increment & Number of Municipalities & $\%$ of Coca Increment \\
\hline Antioquia & 32664.68 & 32 & 98.5 & 15 & 1.49 \\
\hline Bolivar & 24528.43 & 12 & 98.1 & 3 & 1.91 \\
\hline Boyacá & 1642.55 & 6 & 91.9 & 8 & 8.12 \\
\hline Cordoba & 9185.79 & 3 & 99.4 & 2 & 0.59 \\
\hline Cundinamarca & 387.80 & 1 & 72.9 & 4 & 27.04 \\
\hline Santander & 5684.19 & 6 & 85.2 & 16 & 14.79 \\
\hline Caquetá & 32909.56 & 14 & 97.9 & 2 & 2.11 \\
\hline Putumayo & 51802.45 & 9 & 87.2 & 2 & 12.82 \\
\hline
\end{tabular}

Table 2. Comparison between municipalities with and without forest fires in coca increment in forest areas (2000 - 2010). Note that a very high percentage of coca increment occurred in forest areas where forest fires were detected.

\begin{tabular}{|c|c|c|c|c|c|}
\hline \multirow[b]{2}{*}{ Department } & \multirow{2}{*}{$\begin{array}{l}\text { Total Coca Increment } \\
\text { in Forest Areas (ha) }\end{array}$} & \multicolumn{2}{|c|}{ Municipalities with Fires in Coca Increment Areas } & \multicolumn{2}{|c|}{ Municipalities without Fires in Coca Increment Areas } \\
\hline & & $\begin{array}{c}\text { Number of } \\
\text { Municipalities }\end{array}$ & $\begin{array}{l}\% \text { of Coca Increment } \\
\text { in Forest Areas }\end{array}$ & $\begin{array}{c}\text { Number of } \\
\text { Municipalities }\end{array}$ & $\begin{array}{l}\% \text { of Coca Increment } \\
\text { in Forest Areas }\end{array}$ \\
\hline Antioquia & 14690.61 & 32 & 99.1 & 15 & 0.95 \\
\hline Bolivar & 6756.04 & 12 & 100 & 3 & 0.00 \\
\hline Boyaca & 973.72 & 6 & 93.4 & 8 & 6.57 \\
\hline Cordoba & 1678.17 & 3 & 100 & 2 & 0.00 \\
\hline Cundinamarca & 40.02 & 1 & 53.4 & 4 & 46.55 \\
\hline Santander & 2482.08 & 6 & 92.3 & 16 & 7.664 \\
\hline Caqueta & 10530.19 & 14 & 99.9 & 2 & 0.079 \\
\hline Putumayo & 19416.12 & 9 & 93.7 & 2 & 6.272 \\
\hline
\end{tabular}

Logit:

$P\left(\operatorname{coc}_{p l_{i}}=1 \mid x\right)=-2.2342+0.1211 *$ fires $_{i}+0.0281 *$ $\log \left(\right.$ inhab $\left._{i}\right)+0.007 *$ needs $_{i}+0.135 * \log \left(\operatorname{expl}_{i}\right)$

Probit:

$P\left(\operatorname{coc}_{p l_{i}}=1 \mid \boldsymbol{x}\right)=-1.6972+0.1059 *$ fires $_{i}+0.0059 *$ $\log \left(\right.$ inhab $\left._{i}\right)+0.0055 * \operatorname{need}_{i}+0.0 .1111 * \log \left(\operatorname{expl}_{i}\right)$

These results are summarized in Table 4 below. When all other variables are held fixed, one more fire in the forest will increase the probability of the increment of coca plantations by $0.0004 \%, 0.1211 \%$ and $0.1059 \%$ for the LPM, Logit and Probit models respectively while a $1 \%$ increase in the log of basic unsatisfied needs will increase the probability by $0.0042 \% ; 0.0070 \%$ and $0.0055 \%$ respectively. Finally, a $1 \%$ increase in the log of expulsion increases the probability of the increment of coca plantations by $0.0650 \%, 0.135 \%$ and $0.1111 \%$ for the LPM, Logit and Probit models respectively, when all other variables are held fixed.
Note that all the results are based on a threshold value of 0.4 for all models. It is important to underline that the models' outputs are always probabilities (i.e., real numbers between 0 and 1). We need to define a threshold based on a goodness of fit in order to assign success and failure. We used the percentage of correctly predicted increase in coca plantation as a goodness of fit and maximized it subject to different values of the threshold. The best performing one was 0.4 , which is why this value was subsequently used as the critical threshold. In simpler terms, we chose the threshold that maximized the percent of correctly predicted coca plantations; this explains to some extent why this percentage is above $85 \%$ for all the models.

The Linear Probability Model has the advantage that is easy to interpret but it has the disadvantages that the predictions (fitted probabilities) can be less than zero or greater than one. In addition, the partial effect of any explanatory variable (appearing in level form) is constant. However, the coefficients of the Linear model show that this model is not appropriate for describing the data. In addition, the partial effects are constant for all explanatory variables. 
Table 3. LPM, Logit and Probit estimates of coca plantations.

\begin{tabular}{|c|c|c|c|}
\hline Explanatory Variables & $\operatorname{LPM}^{(\mathrm{a})}(\mathrm{OLS})$ & Logit $^{\text {(a) }}$ (MLE) & Probit $^{(a)}$ (MLE) \\
\hline Constant & $-0.6477^{(\mathrm{b})}$ & $-9.1721 *$ & $-4.4680 *$ \\
\hline Fires in forest & $0.0004 *$ & $0.4973 *$ & $0.2788^{*}$ \\
\hline (Log) Inhabitants in rural areas & 0.0245 & 0.1152 & 0.0156 \\
\hline Basic unsatisfied needs & $0.0042 *$ & $0.0288^{*}$ & $0.0146^{*}$ \\
\hline (Log) Expulsion & $0.0650 *$ & $0.5544 *$ & $0.2926^{*}$ \\
\hline Log-likelihood value & -- & -101.0538 & -101.1484 \\
\hline Percent correctly predicted ${ }^{(\mathrm{d})}$ & 86.69 & 93.35 & 93.35 \\
\hline F-statistic & $52.08 *$ & -- & -- \\
\hline LR-statistic & -- & $279.32 *$ & $279.13^{*}$ \\
\hline
\end{tabular}

Note: (a) The first column reports the coefficients' estimates from the Linear Probability Model (LPM) calculated using OLS. The second and third column report the coefficients estimates obtained with the Logit and Probit models, respectively. Both of them were calculated using maximum likelihood estimation (MLE). (b) The star (*) denotes coefficients" estimates that are statistically significant at the $5 \%$ level. (c) This is just the usual R-squared reported for OLS. (d) These were predicted using the threshold value 0.4 for all models.

Table 4. Magnitude of the marginal effects of statistically significant explanatory variables (LPM, Logit and Probit Estimates).

\begin{tabular}{|c|c|c|c|}
\hline Explanatory Variables & $\operatorname{LPM}^{(a)}($ OLS $)$ & Logit $^{(b)}$ (MLE) & Probit $^{(\mathrm{c})}$ (MLE) \\
\hline Constant & $-0,6477$ & -2.2342 & -1.6972 \\
\hline Fires in forest & 0.0004 & 0.1211 & 0.1059 \\
\hline (Log) Inhabitants in rural areas & 0,0245 & 0.0281 & 0.0059 \\
\hline Basic unsatisfied needs & 0.0042 & 0.0070 & 0.0055 \\
\hline
\end{tabular}

Instead the Logit and Probit models imply diminishing magnitudes of the partial effects. It is important to highlight those municipalities where an increase of one fire would be reflected in moving from below to above the pre-established threshold $(\widetilde{\alpha}=0.4$.). Examples of this situation are Cicuco (Bolivar), Corcona (Antioquia) and Betulia (Santander). The Percent Correctly Predicted (PCP) is a measure of the goodness of fit but has the disadvantage that it treats different probabilities in the same way [29]. In this case the PCP considers a probability of 0.41 equal to a probability of, e.g. 0.99 , despite the fact that the latter value is clearly greater. The Logit and Probit models provide similar results despite different functional forms. However, the equation of the Logit model is much simpler than that of the Probit model. Fig. (7) therefore shows probabilities based on the coefficients for the Logit model by municipality. When there is one more fire, then fourteen municipalities move from below the threshold level of 0.4 to above. Examples of these municipalities are Uramita (Antioquia), Tierralta (Córdoba), San Jacinto (Bolivar) and Muzo (Boyacá) (Fig. 5).

\subsection{Model Validation}

Comparing the graphs from the LPM, Logit and Probit models provided in Fig. (6), it can be observed that in the LPM model, the actual and fitted values do not correspond to each other. Therefore, this model is not appropriate. In addition, the residual values show several outliers.

Comparing the performance of the Logit and Probit models in Fig. (7), it can be observed that the fitted values fit well to the actual values. Additionally, the residuals have fewer outliers.

The 10 fold out cross-validation method was used to validate the Logit Model. The original population of 526 municipalities was divided into 10 groups. Of these, 9 were used to fit the model and 1 was used to evaluate the model. The mean corrected classified value was 0.92 , which indicates that the model is successful in $92 \%$ of cases. The results of the leave-one-out cross-validation method with 500 iterations showed that the proportion of the mean corrected classified values was around 0.93 , which indicates that the model is incorrect in only $7 \%$ of cases.

\section{DISCUSSION}

There are three important findings that can be drawn from this study. The first finding is that there is a relationship between coca increment and number of forest fires. The second is that if coca cultivation increases, it is likely that this will lead to further deforestation $[9,27]$ even when the size of the plot is very small. The third finding is that fires around established coca areas and the socioeconomic variable expulsion can be used as indicators of future coca increment in forest areas.

The density of fires analysis per municipality shows that fire is used to clear forest to grow coca. Even though in many cases the majority of fires occurs in areas where coca increment is found, in some regions this is not the case. For instance, in Antioquia and Putumayo all municipalities have higher density of fires in coca increment areas compared to 


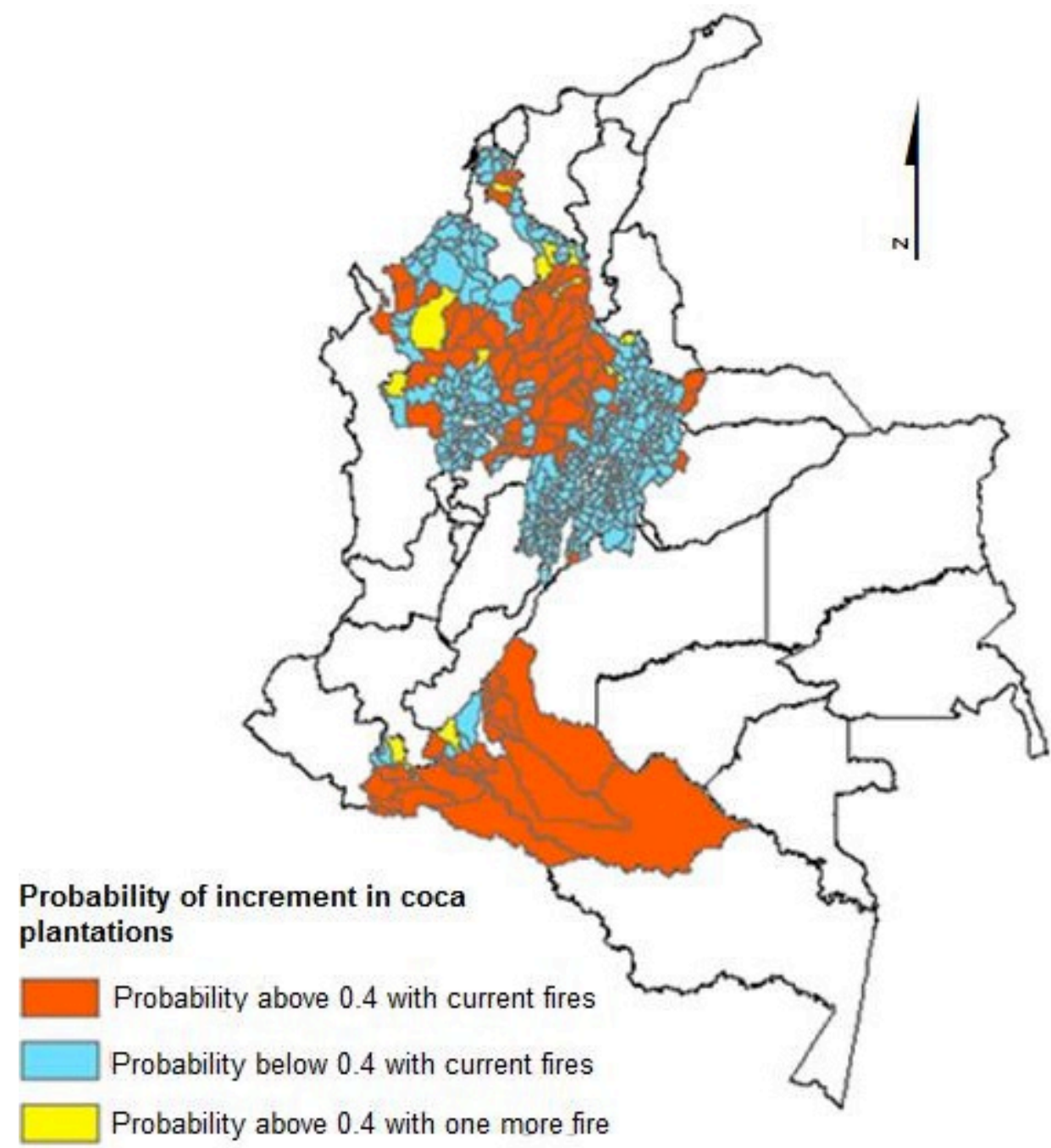

Probability above 0.4 with one more fire

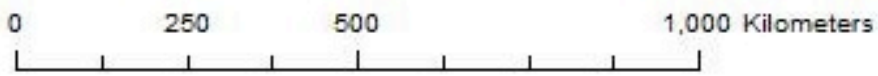

Fig. (5). Probability of coca increment - Logit Model.

the other areas. In Bolivar and Caquetá there is no particular pattern found which relates to the density of fires showing that this varies by municipality. An explanation could be the variable rate or concentration at which new coca plantations are occurring across regions. For instance, coca plantations in Antioquia have increased significantly in the last years compared to other areas where the rate of increase is slower [30].

However, the majority of coca increment in forest areas in all municipalities in the study area is spatially associated with fires. Analyzing the percentage of coca increment having a spatial relation with fires (Table 1), four of the departments belonging to the Central Region show a higher percentage (more than 90\%) of coca increment in areas where fires and coca increment are spatially related. For example, Boyacá and Cundinamarca show a percentage of coca increment higher than $70 \%$. A similar pattern can be observed in Putumayo-Caqueta. The percentage of coca increment which is related to fires is higher than $97 \%$ and $87 \%$ in these regions, respectively. Moreover, when considering coca increment in forest areas only, a similar situation is presented (Table 2). In all departments where

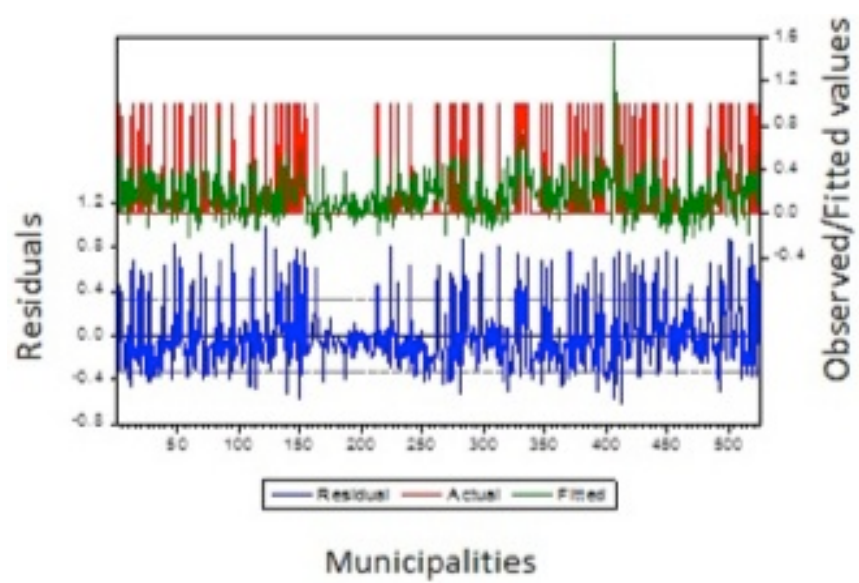

Fig. (6). Fitted - Actual and Residual values LPM. 


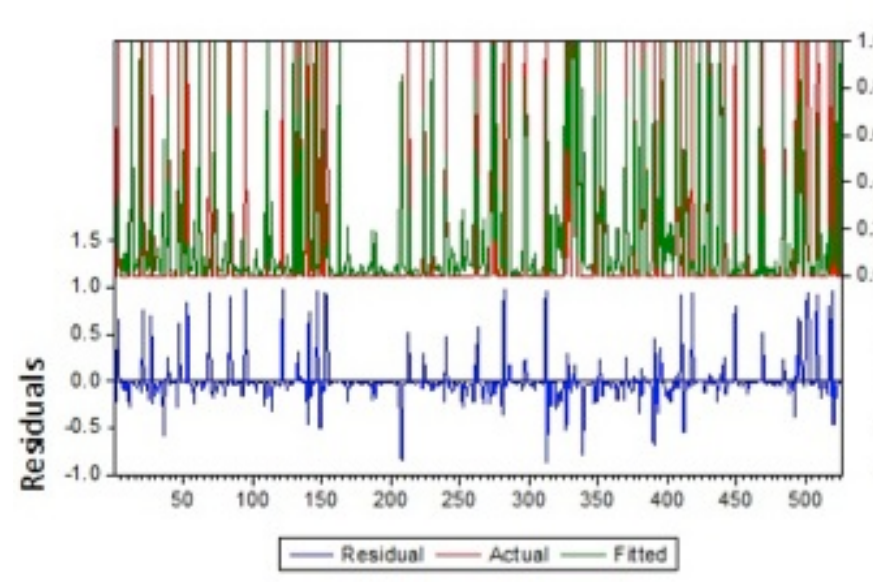

a.

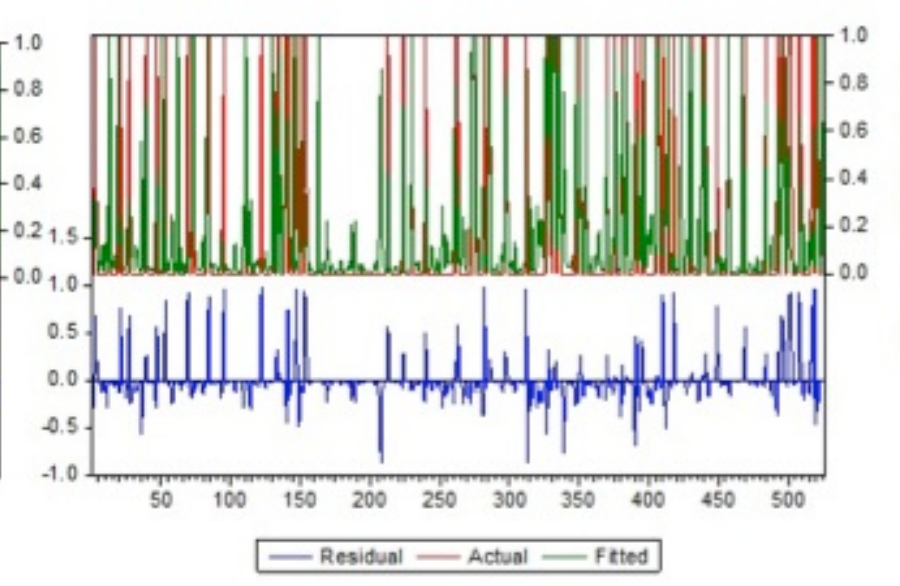

b.

\section{Municipalities}

Fig. (7). Fitted - Actual and Residual values a. Logit b. Probit.

a coca increment in forest areas can be observed, fire is used as a management tool. Comparing the municipalities with fires related to coca increment and municipalities without

fires related to coca increment, it becomes clear that $90 \%$ of this increment is related to fires in forested areas. The situation in Cundinamarca, however, is different. One municipality has $53.45 \%$ of the total coca increment in the forest in this department with fires spatially related while another four do not, yet together they represent $46.55 \%$ of the coca increment.

It is interesting to note from Tables $\mathbf{1}$ and $\mathbf{2}$ that in most cases when there is coca increment this results in fire activities. Thus the relationship between fires and coca increment works very well when coca is increasing. In brief, nearly in all municipalities when coca is increasing, fires occur in the 10 year observation period. This is an important finding as this means that there are hardly any places where coca increment has not had an occurrence of fires. This may indicate that fire is an important tool to open new areas to grow coca in these areas. That said, forest fire cannot be attributed to coca in all cases although it does strongly influence the expansion of the agricultural frontier [5].

In order to understand the sequence between fire, deforestation and coca, the relationship between coca increment and deforestation and fire and deforestation was analyzed. Subsequently, the analysis between fire and coca increment was made.

The Pearson correlation between coca increment and deforestation for the period 2001 to 2010 shows a positive relationship. In general, in the municipalities of the Central Region located over the Andean, coca increment is associated with up to $60 \%$ of the total deforestation. In Putumayo-Caquetá Region, coca increment is associated in general with a percentage higher than $80 \%$ in Putumayo, specifically at the beginning of the period, and up to $40 \%$ in Caquetá.
Some municipalities belonging to the departments in the Central Region are located over the Andean Mountains. Putumayo and Caquetá are located in the Amazonian rainforest. As coca growers tend to hide the crops under the

trees, these regions are consequently highly vulnerable to degradation. In addition, the lack of governance, insufficient policing, population growth and armed conflicts increase the threat of coca expansion and subsequent deforestation in these regions.

The different coca dynamics among regions can be associated with different projects implemented by the government. For instance, the project called 'Milk for cocaine' backed by $\$ 5.3$ million from the United Nations [31] in San Vicente del Caguán is aimed at boosting dairy farming. In this municipality it is therefore unlikely that coca expansion and deforestation or coca and fires are related.

The Pearson correlation between fire and deforestation for the period 2000 to 2010 shows a strong positive relationship (Pearson Coefficient $=0.930$ ). This indicates that as shown in previous studies $[6,8,19]$, there is a strong correlation between fires and deforestation. Accordingly, if there are new expanding activities of coca growth into forest areas, deforestation can be linked to coca increment and population dynamics in coca-growing areas [12]. However, the correlation between fire and deforestation only holds in places where the climatic conditions favor forest fire ignition, for instance in the pacific region, which is characterized by a very humid climate, forest fires are rare.

The Logit and Probit models show that in general fire data together with socio-economic variables can be used to predict potential new coca crops in forest areas at the municipality level. Comparing the three socioeconomic factors used in the models, expulsion shows the highest probability of the occurrence of new coca plantations when all the other variables are held fixed. This variable is related to the presence of illegal groups which are founded in part through the business of illegal drugs. Additionally, this can be used as a coca indicator to highlight the presence of 
illegal groups in the area. Nonetheless, in Colombia it is challenging to obtain up-to-date socioceconomic data. Therefore, fire in forest areas can potentially be used as a first indicator of new coca plantations in the forest. Since fire

data are easily available on the internet, this offers interesting monitoring possibilities at low costs and in near real-time.

\section{CONCLUSION}

The study demonstrates that most of the new coca plantations are found in forest areas and that fire is associated with them. In addition, the study shows that the correlation between fire and deforestation is high, supporting previous work on the possibility of using fire as an indicator of deforestation. Moreover, a high correlation was found between coca increment and deforestation. In general new coca plantations and deforestation patterns show a stronger correlation at department level than at municipality level. However, the level of influence is different depending on the geographical location of the region and the area of each municipality.

However, there are clearly limitations associated with this study. Errors can be found in the fire dataset, e.g. in the forest mask and in the census of coca areas. In addition, the method will only work in areas where the conditions favor the occurrence of fire. The analysis was carried out with a dataset of 10 years and shorter time periods could be examined in order to be able to detect potentially new coca fields evolving at an earlier stage and to understand better the sequence of coca cultivation.

The model was developed for Colombia through yearly monitoring of LANDSAT type data, and subsequent aerial surveys already exist. However, the model could be used and applied in other countries where some potential new coca growing areas could be missed by the manual interpretation of satellite imagery, where resources are limited in terms of carrying out satellite image interpretation and where cloud cover persists. The model complements existing surveys and potentially detects coca expansion. In the future the models could be extended to other variables to better understand coca dynamics, for instance, eradication, road density and climatic conditions.

There are still many things to understand concerning the relation between fires and new coca plantations in forest areas and how this is related to deforestation, which is always subject to data availability. The results should be used carefully because there are many factors influencing both coca increment and fires in forest areas, which differ across regions. However, this study can potentially contribute to the prevention of the expansion of coca plantations in some forest areas.

\section{CONFLICT OF INTEREST}

The views expressed here in are those of the authors and do not necessarily reflect the views of the United Nations.

\section{ACKNOWLEDGEMENTS}

We would like to thank the United Nations Office on Drugs and Crime for facilitating the data regarding coca plantations, the Instituto de Hidrología, Meteorología y Estudios Ambientales (IDEAM) for providing the deforestation maps from the REDD project in Colombia and Diego Luna from the Universidad Nacional de Colombia.

\section{REFERENCES}

[1] Silvestrini RA, Soares-Filho BS, Nepstad D, Coe M, Rodrigues, H, Assunção, R. Simulating fire regimes in the Amazon in response to climate change and deforestation. Ecol Appl 2011; 21: 1573-90.

[2] Food and Agriculture Organization of the United Nations (FAO) Evaluación de los Recursos Forestales Mundiales 2010. Food and Agriculture Organization of the United Nations: Rome, Italy, 2010.

[3] Cabrera E, Vargas D, Galindo G, et al. Memoria técnica de la cuantifi cación de la deforestación histórica nacional - escalas gruesa y fina. Instituto de Hidrología, Meteorología, y Estudios Ambientales-IDEAM 2011.

[4] Morton DC, DeFries RS, Randerson JT, Giglio L, Schroeder W, Van Der Werf GR Agricultural intensification increases deforestation fire activity in Amazonia. Glob Change Biol 2008; 14: $2262-75$.

[5] Armenteras D, Retana J. Dynamics, patterns and causes of fires in Northwestern Amazonia. PLoS ONE 2012; 7: e35288.

[6] Eva H, Fritz S. Examining the potential of using remotely sensed fire data to predict areas of rapid forest change in South America. Appl Geog 2003; 23: 189-204.

[7] Giglio L, van der Werf GR, Randerson T, Collatz GJ, Kasibhatla P. Global estimation of burned area using MODIS active fire observations. Atmos Chem Phy Discuss 2005; 5: 11091-141.

[8] Armenteras D, Rudas G, Rodriguez N, Sua S, Romero M. Patterns and causes of deforestation in the Colombian Amazon. Ecolog Indicat 2006; 6: 353-68.

[9] Armenteras-Pascual D, Retana-Alumbreros J, Molowny-Horas R, Roman-Cuesta RM, Gonzalez-Alonso F, Morales-Rivas M. Characterising fire spatial pattern interactions with climate and vegetation in Colombia. Agric For Meteorol 2011; 151: 279-89.

[10] Eva H, Lambin EF. Fires and land-cover change in the tropics:a remote sensing analysis at the landscape scale. J Biogeog 2000; 27: 765-76.

[11] Armenteras D, Rodriguez N, Retana J. Landscape Dynamics in Northwestern Amazonia: An Assessment of Pastures, Fire, Illicit Crops as Drivers of Tropical Deforestation 2013; p. 8.

[12] Dávalos LM, Bejarano AC, Hall MA, Correa HL, Corthals A, Espejo OJ. Forests and drugs: coca-driven deforestation in tropical biodiversity hotspots. Environ Sci Technol 2011; 45: 1219-27.

[13] Dourojeanni M. Environmental impact of coca cultivation and cocaine production in the amazon region of Peru. Bulletin UNODC 1992; pp. 37-53.

[14] Viña A, Echavarria F, Donald R. Satellite change detection analysis of deforestation rates and patterns along the Colombia - Ecuador border. Royal Swedish Academy of Science 2004.

[15] Bradley AV, Millington AC. Coca and colonists: quantifying and explaining forest clearance under coca and anti-narcotics policy regimes. Ecol Soc 2008; 13: 31 .

[16] Perez, E. Agricultura, Cultivos Ilicitos y Desarrollo Rural en Colombia. In: Debate Agrario (Lima) 2006; vol. 41.

[17] Rincon A. Coca (Erythroxylon coca) crops and socialenvironmental conflicts. A spatial Analysis 2010.

[18] UNODC Colombia Coca Survey 2006.

[19] Dávalos LM, BejaranoAC, Correa, HL. Disabusing cocaine: Pervasive myths and enduring realities of a globalised commodity. Int J Drug Policy 2009; 20: 381-6.

[20] UNODC Analisis Multitemporal de los Cultivos de Coca Período 2001-2006, 2008.

[21] Davies DK, Ilavajhala S, Wong MM, Justice CO. Fire information for resource management system: Archiving and distributing MODIS active fire data. IEEE Trans Geosci Remote Sens 2009; 47: 72-9.

[22] Giglio L, Descloitres J, Justice CO, Kaufman YJ. An enhanced contextual fire detection algorithm for MODIS. Remote Sens Environ 2003; 87: 273-82.

[23] Murali KS, Hedge R. Patterns of tropical deforestation. J Tropical Forest Sci 1997; 9: 465-76. 
[24] Departamento Nacional de Estadística (DANE) Ficha técnica porcentaje de la poblacion total que vive en zonas rurales 2012.

[25] Accion Social Onservatorio Nacional de desplazamiento forzado. Disminución del desplazamiento forzado 2009.

[26] Sanchez F, Diaz AM. A geography of illicit crops (Coca leaf) and armed conflicts in Colombia 2004.

[27] Payam R, Lei T, Huan L. Arizona State University 2008.
[28] Armenteras D, Rodríguez N, Retana J, Morales M. Understanding deforestation in montane and lowland forests of the Colombian Andes. Regional Environmental Change 2011; 11: 693-705.

[29] Train K. Discrete Choice Models with Simulation. Cambridge: Cambridge University Press 2007.

[30] UNODC Colombia. Censo de cultivos de coca 2010. 2011.

[31] UNODCCP Alternative Development in the Andean Area 2000.

Received: May 29, 2014

(C) Gomez et al.; Licensee Bentham Open.

This is an open access article licensed under the terms of the Creative Commons Attribution Non-Commercial License (http://creativecommons.org/licenses/by-nc/3.0/) which permits unrestricted, non-commercial use, distribution and reproduction in any medium, provided the work is properly cited. 